\title{
Health workforce metrics pre- and post- 2015: a stimulus to public policy and planning
}

Francisco Pozo-Martin ${ }^{1}$, Andrea Nove ${ }^{1 *}$, Sofia Castro Lopes ${ }^{1}$, James Campbell ${ }^{2,3}$, James Buchan ${ }^{4}$, Gilles Dussault ${ }^{5}$, Teena Kunjumen², Giorgio Cometto ${ }^{3}$ and Amani Siyam²

\begin{abstract}
Background: Evidence-based health workforce policies are essential to ensure the provision of high-quality health services and to support the attainment of universal health coverage (UHC). This paper describes the main characteristics of available health workforce data for 74 of the 75 countries identified under the 'Countdown to 2015 ' initiative as accounting for more than 95\% of the world's maternal, newborn and child deaths. It also discusses best practices in the development of health workforce metrics post-2015.

Methods: Using available health workforce data from the Global Health Workforce Statistics database from the Global Health Observatory, we generated descriptive statistics to explore the current status, recent trends in the number of skilled health professionals (SHPs: physicians, nurses, midwives) per 10000 population, and future requirements to achieve adequate levels of health care in the 74 countries. A rapid literature review was conducted to obtain an overview of the types of methods and the types of data sources used in human resources for health (HRH) studies.

Results: There are large intercountry and interregional differences in the density of SHPs to progress towards UHC in Countdown countries: a median of 10.2 per 10000 population with range 1.6 to 142 per 10000 . Substantial efforts have been made in some countries to increase the availability of SHPs as shown by a positive average exponential growth rate (AEGR) in SHPs in 51\% of Countdown countries for which there are data. Many of these countries will require large investments to achieve levels of workforce availability commensurate with UHC and the health-related sustainable development goals (SDGs). The availability, quality and comparability of global health workforce metrics remain limited. Most published workforce studies are descriptive, but more sophisticated needs-based workforce planning methods are being developed.
\end{abstract}

Conclusions: There is a need for high-quality, comprehensive, interoperable sources of HRH data to support all policies towards UHC and the health-related SDGs. The recent WHO-led initiative of supporting countries in the development of National Health Workforce Accounts is a very promising move towards purposive health workforce metrics post-2015. Such data will allow more countries to apply the latest methods for health workforce planning.

Keywords: Health workforce, Health systems, Metrics, Countdown, Data, Densities, Low- and middle-income countries, Universal health coverage, Sustainable development goals

\footnotetext{
* Correspondence: andrea.nove@icsintegrare.org

${ }^{1}$ Instituto de Cooperación Social Integrare, calle Balmes 30, 3-1, 08007

Barcelona, Spain

Full list of author information is available at the end of the article
} 


\section{Background}

The case for universal health coverage (UHC) is wellestablished, but its implications for the health workforce have only recently started to receive attention. Countries working towards UHC need to keep track of the size and composition of their health workforce and to anticipate future need for human resources for health (HRH) [1]. This can be strategically informed by valid and reliable workforce data [2]; without these data, decisionmakers are unable to plan strategically or anticipate future needs $[3,4]$.

The importance of HRH data and the need to improve them has been stressed by the World Health Organization (WHO), the World Bank and the Organization for Economic Co-operation and Development [5-7]. To date, data collection processes and mechanisms have tended to be developed at a country level. There have been attempts to create harmonised regional and global data sets $[8,9]$, but this work requires further development.

Recent data from the International Labour Organization estimate a global shortfall of over 10 million health workers and affecting principally countries with the highest burden of mortality and morbidity [10]. The focus of this paper is on the 75 'Countdown to 2015' countries. Countdown to 2015 was a global movement which tracked progress towards the health-related Millennium Development Goals (MDGs) in the 75 countries where more than $95 \%$ of maternal and child deaths occurred [11]. The Countdown to 2015 collaboration has now evolved into the 'Countdown to 2030 for Reproductive, Maternal, Newborn, Child, and Adolescent Health and Nutrition' initiative, which will continue the focus on high-burden countries, particularly in Sub-Saharan Africa and South Asia [12], making these 75 countries still highly relevant in the post-2015 era.

This paper uses two health worker density thresholds to assess the $\mathrm{HRH}$ situation in the Countdown countries. Firstly, the 2006 World Health Report [13] stated that countries with fewer than 22.8 physicians, nurses and midwives per 10000 population were highly unlikely to be able to provide $80 \%$ coverage of the most basic health services [14]. Secondly, WHO recently developed an 'SDG Index threshold' as an indicative minimum density representing the need for health workers to achieve the health targets of the Sustainable Development Goals (SDGs). The value of the threshold was determined to be 4.45 doctors, nurses and midwives per 1000 population (or 44.5 per 10000 ) [15].

These two thresholds are both needs-based yet vary in interpretation: countries below the 22.8 threshold may be thought of as having too few health workers to meet even the most basic health needs, whereas the 44.5 threshold can be thought of as a step forward in identifying the minimum health workforce requirements to achieve the health-related SDGs.
As stated in the 2006 World Health Report, these thresholds 'are not a substitute for specific country assessments of sufficiency, nor do they detract from the fact that the effect of increasing the number of health workers depends crucially on other determinants' [13]. Additionally, there are limitations in both these thresholds and the quality of the data used to calculate countries' health worker densities [16-19]. However, in the absence of robust estimates of $\mathrm{HRH}$ development, thresholds offer a common comparative value against which countries can be monitored to check $\mathrm{HRH}$ progress or the lack of it [20]. Therefore, this study aimed to (a) describe $\mathrm{HRH}$ metrics in the 75 Countdown countries using a global and comparable source and (b) describe and assess some commonly used HRH metrics, their sources of data, and the methods used to analyse $\mathrm{HRH}$ data in the research literature. The fulfilment of these two objectives allows us to make some recommendations about how HRH metrics (and the data that feed into them) could be developed in the SDG era.

\section{Methods}

To describe the characteristics of $\mathrm{HRH}$ metrics in the 75 Countdown countries, we used two indicators of workforce availability: (1) number of skilled health professionals (SHP numbers: nurses, midwives and physicians) and (2) density of skilled health professionals per 10000 population (SHP density). We extracted data on SHP numbers from 2004 to 2014 for each of the 75 Countdown countries from the WHO Global Health Workforce Statistics database [21]. This database compiles data from four main sources: population censuses, labour force and employment surveys, health facility assessments and routine administrative information systems. Most of the data from administrative sources are derived from published national health sector reviews and/or official reports to WHO offices.

No SHP data were available for South Sudan, so this country was excluded. To calculate SHP densities for each of the remaining 74 countries, country data on SHP numbers were divided by the population size [22] of each country in the relevant year. We used descriptive statistics to examine the current levels of SHP density and their association with (1) gross domestic product (GDP) and health expenditure and (2) country-specific health outcomes and health care coverage indicators. We used Pearson's $r$ to measure the correlation between SHP density and these indicators. We conducted analysis by region by allocating each country to one of the seven UNICEF regions (the regional presentation of similar analysis presented by the Countdown initiative).

We used descriptive statistics to explore trends over time in SHP density for 53 of the 54 Countdown countries which reported SHP numbers for two points in 
time: 2004 (or closest year prior to 2004-the oldest data are from 1997 for Angola) and the most recent year available (see Additional file 1): Uganda was excluded from the trend analysis due to a highly discrepant change in the number of SHP reported between 2004 and 2005, the two time points available for this country). For 52 of these 53 countries, it was possible to explore trends over time disaggregated into (1) number of nurses and midwives and (2) number of physicians (the exception was Madagascar, for which such disaggregated data were not available). Trends over time were measured using the average exponential growth rate (AEGR):

$$
\mathrm{AEGR}=\frac{\ln \left(w_{n} / w_{1}\right)}{n}-1
$$

In Eq. 1 above, $w_{1}$ and $w_{n}$ are the first (2004 or nearest) and the latest observations of variable $w$ (either SHP numbers or SHP density) in a period of $n$ years. The AEGR is most suitable to define the growth rate between two points in time for certain demographic indicators, notably labour force and population. The AEGR does not correspond to the annual rate of change measured at a 1-year interval, but rather to an average rate that is representative of the available observations over the entire period.

The rationale behind exploring trends over time in both SHP numbers and SHP densities is that these two indicators measure different things: while changes in SHP numbers measure the effort made by a health care system in increasing the overall availability of skilled health professionals, changes in the SHP density measure reconciles the changes in the availability of SHP given an individual country's population growth.

Looking forward, a final analysis calculated the AEGR required in each Countdown country to reach a density of 44.5 SHP per 10000 population by 2030 .

To complement this analysis and to inform the future development of global HRH metrics, we investigated the types of methods and data sources used in other $\mathrm{HRH}$ studies by means of a rapid literature review. The search was conducted in PubMed, in the Bulletin of the World Health Organization and in Human Resources for Health, using the following four search terms: 'Human Resources for Health,' 'Data,' 'Metrics' and 'Statistics'.

The initial search yielded 1144 papers. This was narrowed down to 237 on the basis of a title review, then to 125 on the basis of an abstract review. From these, 86 were selected for full review according to the following inclusion criteria: (1) used a quantitative approach (or mixed methods including some quantitative), (2) used HRH data, (3) published in or after 2004 and (4) published in English. Only papers from peer-reviewed publications were included (i.e. there was no grey literature). Nearly $90 \%$ of the studies were published from 2007 onwards, reaching its peak in $2013(n=14)$. The final cutoff date for inclusion was May 2015, and the whole process was conducted by one researcher.

Relevant information about the study attributes was extracted and recorded as follows:

- The income level of the countries included in the study (high-, upper-middle, lower-middle and low-income according to the World Bank income classification)

- The type of method used (basic descriptive and inferential statistics, regression analysis, workforce modelling)

- The comparative level where the study was conducted (multi-country, national, national and subnational)

- The health workforce cadre(s) included in the analysis (physicians, nurses, midwives and others)

- The type of data sources (global, national, subnational and administrative, institutional)

- The metrics used (headcounts, densities and others)

- The topic of interest (e.g. migration, distribution, among others)

\section{Results}

HRH metrics in the countdown countries

Wide variations in SHP density were observed; the median SHP density in the 74 countries was 10.2 per 10 000 population, with estimates ranging from 1.6 in Madagascar and Niger to 142 in Uzbekistan. Of the 74 countries, 55 (74\%) fell short of the 22.8 threshold, 8 had a SHP density between 22.8 and 44.5 and 11 had a SHP density of 44.5 or above (see Additional file 1). Most of the countries with very low densities are in subSaharan Africa and South Asia (see Fig. 1).

Figure 2 shows how SHP density varied by UNICEF region. All five Countdown countries in the Central and Eastern Europe region had at least 44.5 SHPs per 10000 population. However, in other regions, SHP densities tended to be much lower.

Figure 3 shows the strong association between World Bank income group [23] and SHP density: 32 (94\%) of the low-income countries had a density $<22.8$, compared with 20 (71\%) lower-middle-income countries and three (18\%) upper-middle- and high-income countries.

Countries with lower SHP densities tended to have worse maternal and newborn health $(\mathrm{MNH})$ outcomes, as illustrated in Figs. 4 and 5 . Figure 4 shows that Countdown countries with higher SHP densities had lower maternal mortality ratios $(r=-0.56, p<0.05)$ according to WHO mortality estimates [24]. Countdown countries in the highest quintile of SHP density (31.2+ SHPs/10 000 population) had a median maternal mortality ratio $11 \%$ of that of countries belonging to the lowest 

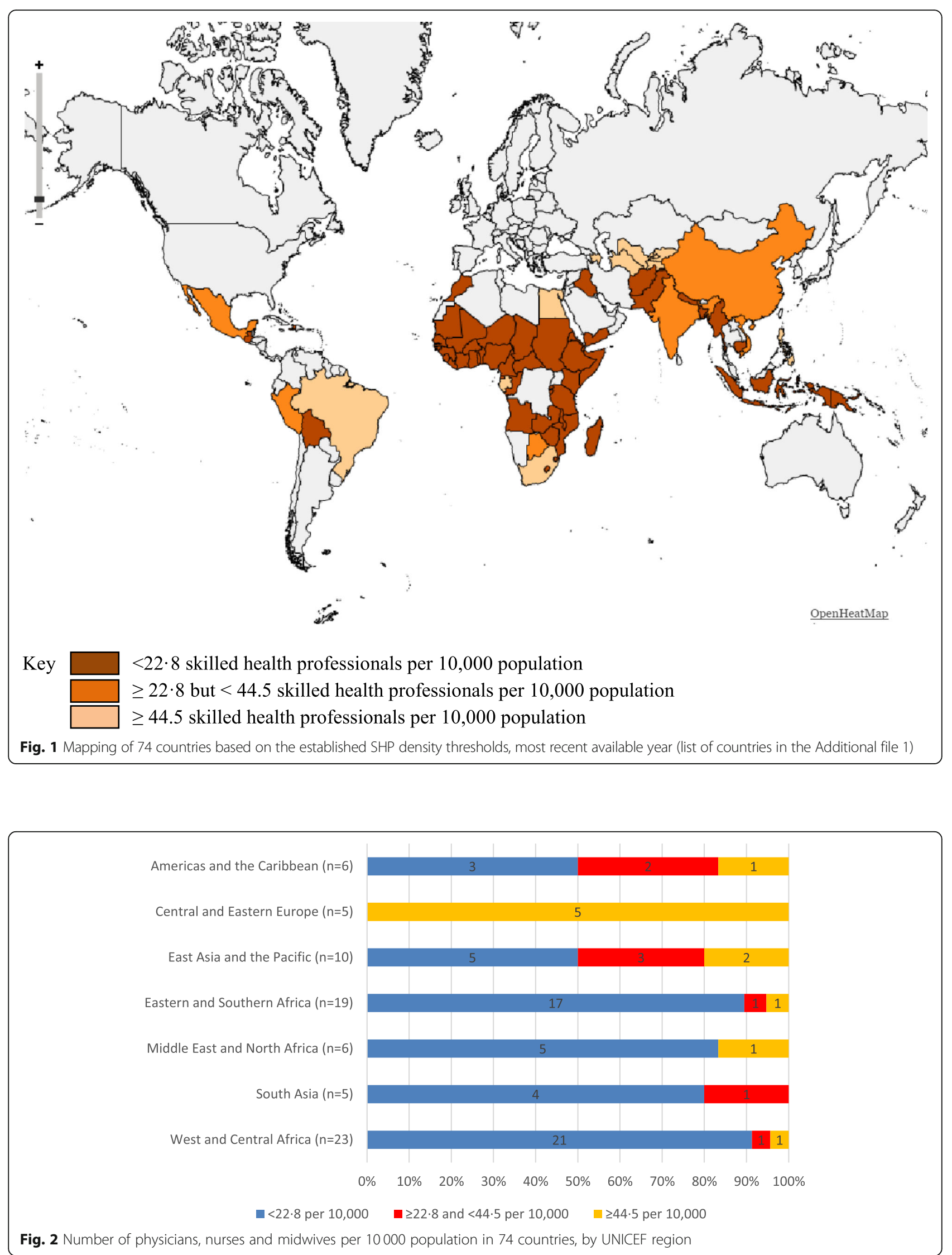

Fig. 2 Number of physicians, nurses and midwives per 10000 population in 74 countries, by UNICEF region 


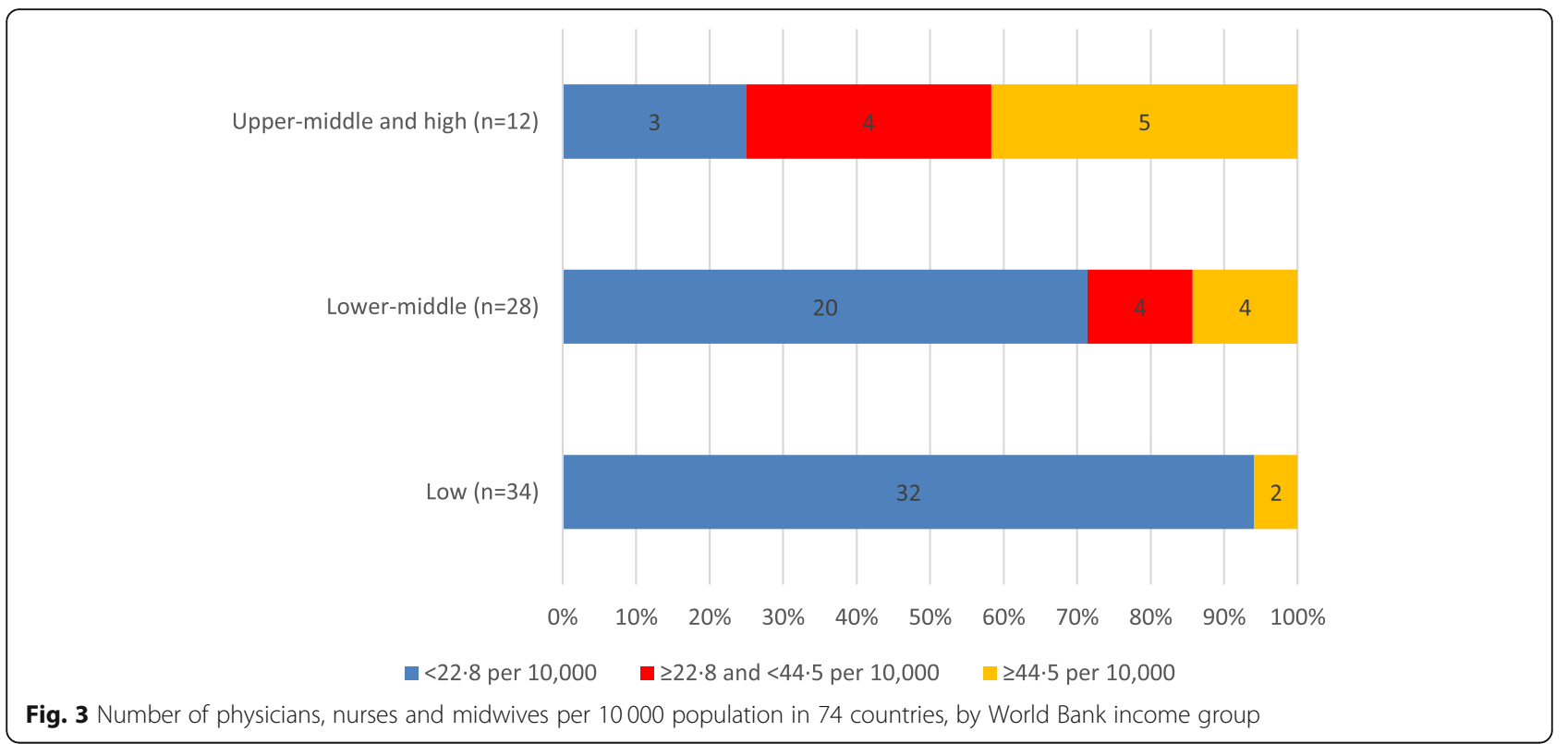

quintile of SHP density (<4.9 SHPs/10 000 population). Figure 5 shows that countries with higher SHP densities had (1) lower stillbirth rates $(r=-0.56, p<0.05)$, (2) lower neonatal mortality rates $(r=-0.45, p<0.05)$ according to Healthy Newborn Network data [25] and (3) lower under-5 mortality rates $(r=-0.48, p<0.05)$ according to UN data [26]. These results cannot prove a causal relationship between health worker density and $\mathrm{MNH}$ outcomes, since strong confounders such as quality of care or social factors are not taken into account in this analysis. However, the contribution of health worker density to the improvement of health outcomes has been shown in other studies [27]. Moreover, it should be noted that, for most Countdown countries, estimates of the maternal mortality ratio and the stillbirth rate are generated by statistical modelling rather than empirical data $[28,29]$. Factors such as GDP and gross national income (GNI) are used as predictors in the modelling, which is bound to affect the observed correlation between mortality estimates and SHP density.

Figure 6 shows that, where data are available, countries with higher SHP density had (1) higher coverage of

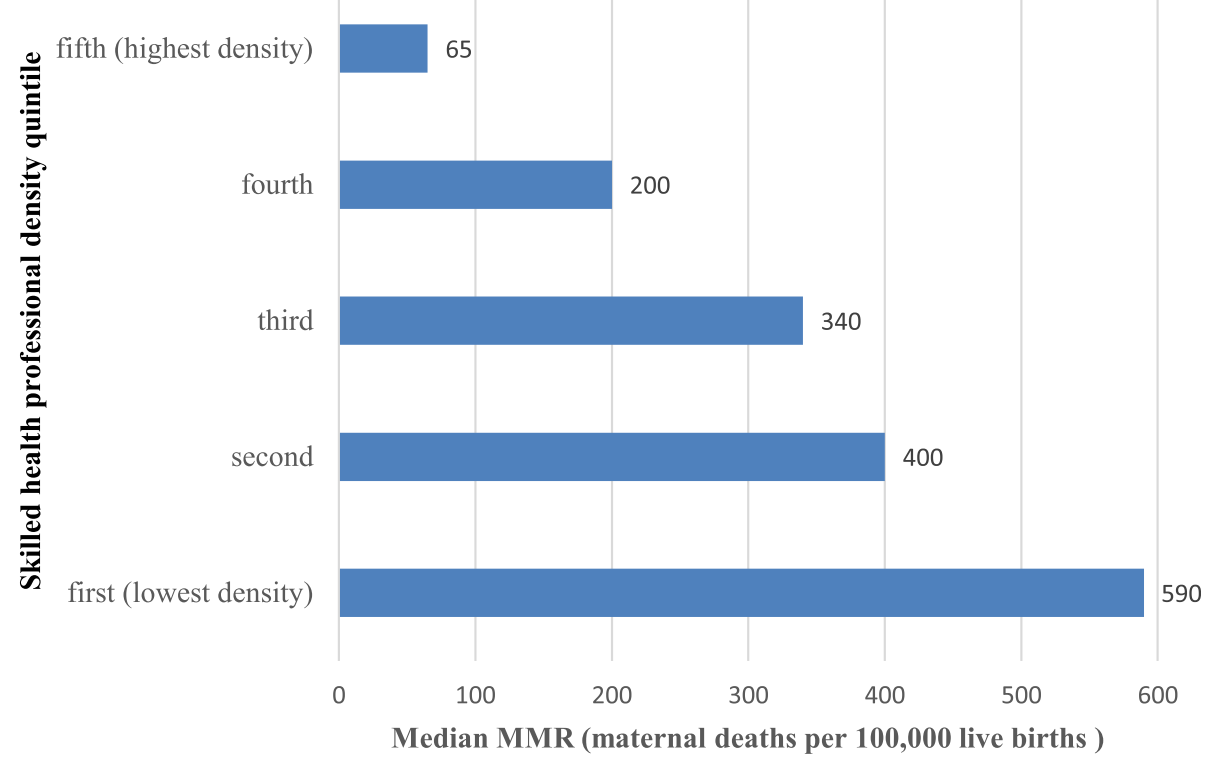

Fig. 4 Median maternal mortality ratio (MMR), by quintiles of number of physicians, nurses and midwives per 10000 population 


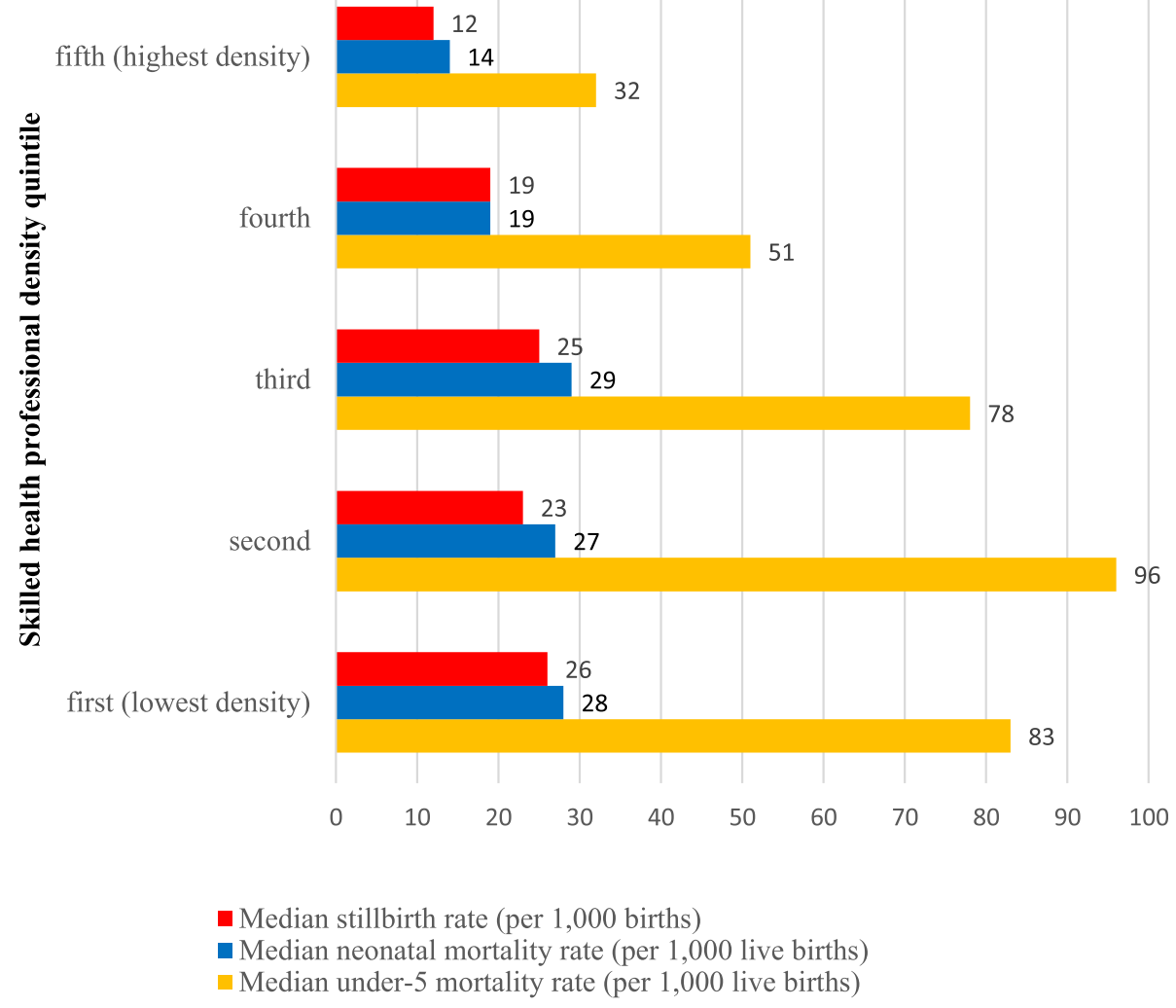

Fig. 5 Median stillbirth, neonatal mortality and under-5 mortality rates, by quintiles of number of physicians, nurses and midwives per 10000 population

antenatal care $(r=0.46, p<0.05)$, (2) higher coverage of skilled birth attendance $(r=0.6, p<0.05)$ and (3) higher coverage of postnatal care $(r=0.40, p<0.05)$ according to Demographic and Health Surveys and UN estimates. $[30,31]$ Countdown countries in the highest quintile of SHP density (31.2+ SHPs/10 000 population) estimate a median skilled birth attendance coverage close to double that of those in the lowest quintile of SHP density $(<4.9$ SHPs/10 000 population).

As measured by the AEGR, of the 53 countries with at least two data points, 27 (51\%) showed an increase in SHP density, 19 (36\%) showed a decrease and the remaining $6(11 \%)$ showed little or no change (AEGR between -1 and 1\%). Figure 7 shows which countries fall into each of these categories: Djibouti, Egypt and the Gambia all showed a positive AEGR greater than $10 \%$. On the other hand, in Madagascar, Swaziland, Cameroon and Sierra Leone a large negative AEGR was observed.

By UNICEF regions, Fig. 8 shows the direction of change in AEGR and Fig. 9 its magnitude. In all regions except the Americas \& Caribbean and West \& Central Africa, the number of countries showing a positive AEGR in SHP density was larger than the number showing a negative AEGR (Fig. 8). None of the four South Asian countries recorded a decrease in SHP density, and four of the five countries in Middle East and North Africa recorded an increase. On the other hand, countries in West and Central Africa were the least likely to display an increase in density (only five of 18 countries did). The data from West and Central Africa illustrate well the difficulty of keeping pace with a growing population; 7 out of the 18 countries in this region recorded an increase in SHP numbers, but only 5 recorded an increase in SHP density.

Figure 9 shows that, in the 32 out of 53 countries (60\%) with a positive AEGR in SHP numbers, most (22) recorded an increase of $5 \%$ or more, including nine countries with an AEGR of $10 \%$ or more. Middle East and North Africa region was a particularly strong performer. By contrast, East Asia and the Pacific and Americas and the Caribbean regions showed weaker growth.

For the 52 countries for which it was possible to disaggregate the AEGRs in SHP numbers for physicians and for nurses and midwives, there was a positive correlation between the AEGR in the number of physicians and the AEGR in the number of nurses and midwives $(r=0.48, p<$ $0.05)$. Figure 10 shows the range of values underlying this association. Of 18 countries with a negative AEGR for nurses and midwives, half showed a null or positive AEGR for physicians (Swaziland, Chad, Zambia, Malawi, Somalia, 


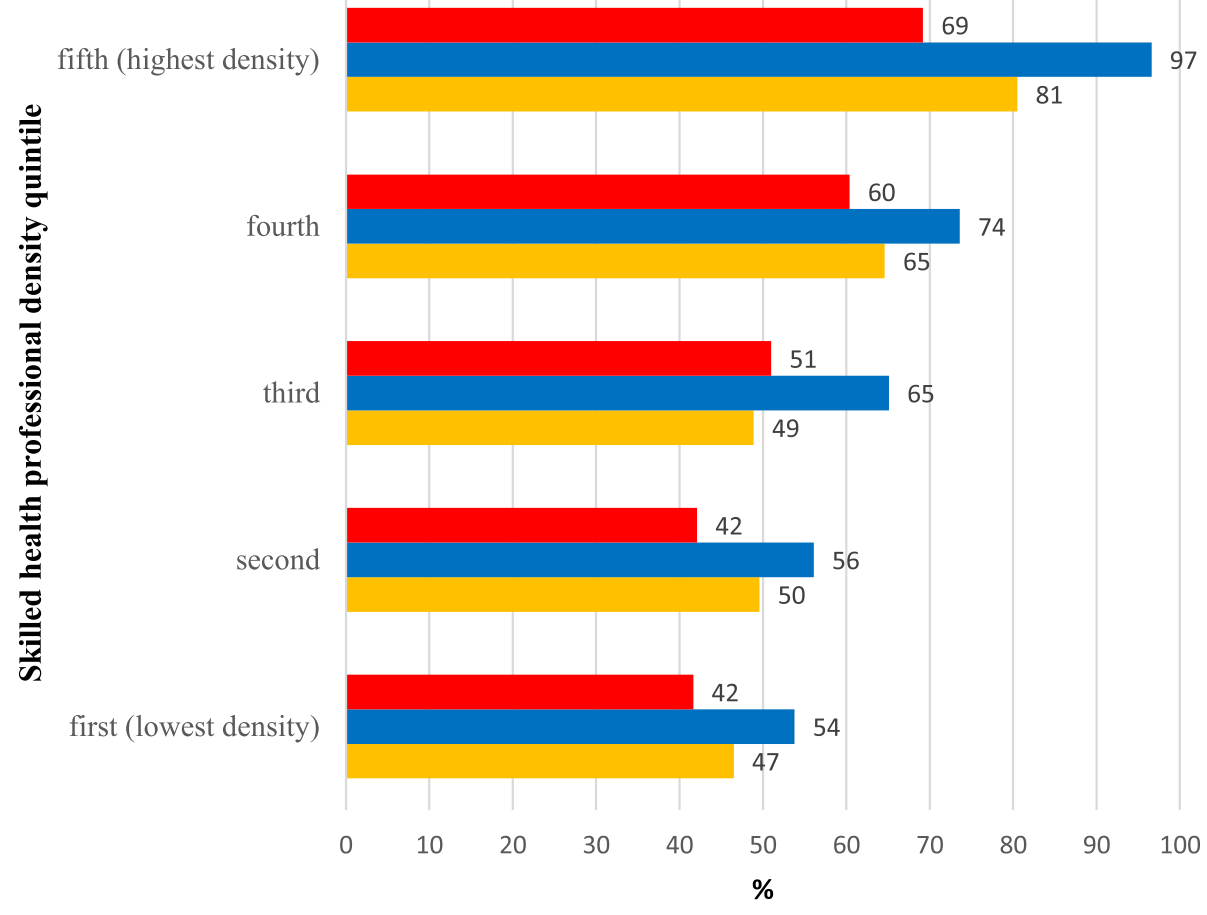

- Median postnatal care coverage

- Median skilled birth attendance coverage

Median antenatal care coverage (4+ visits)

Fig. 6 Median postnatal care coverage/median skilled birth attendance coverage/median antenatal care coverage by quintile of number of physicians, nurses and midwives per 10000 population

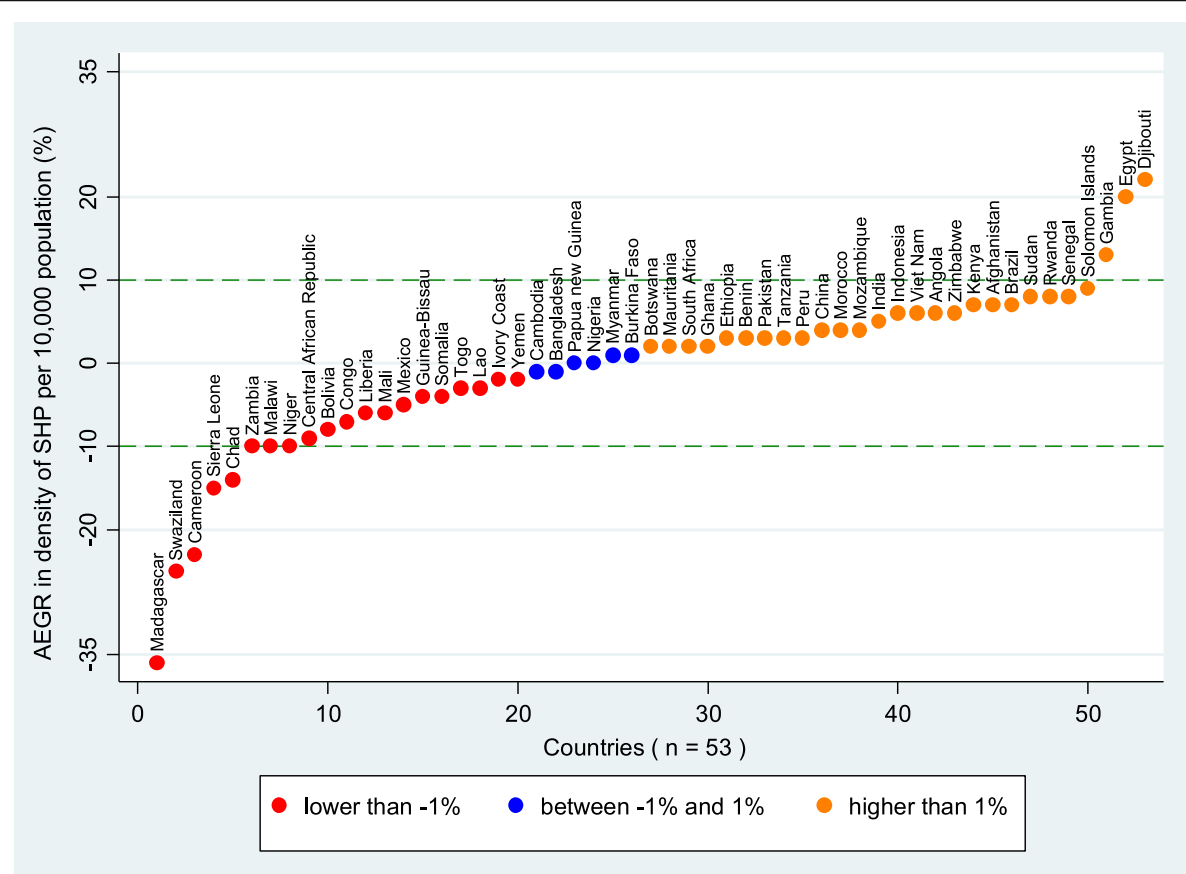

Fig. 7 Average exponential growth rate (AEGR) in number of physicians, nurses and midwives per 10000 population for 53 Countdown countries with more than one data point between 2004 and the latest available year 


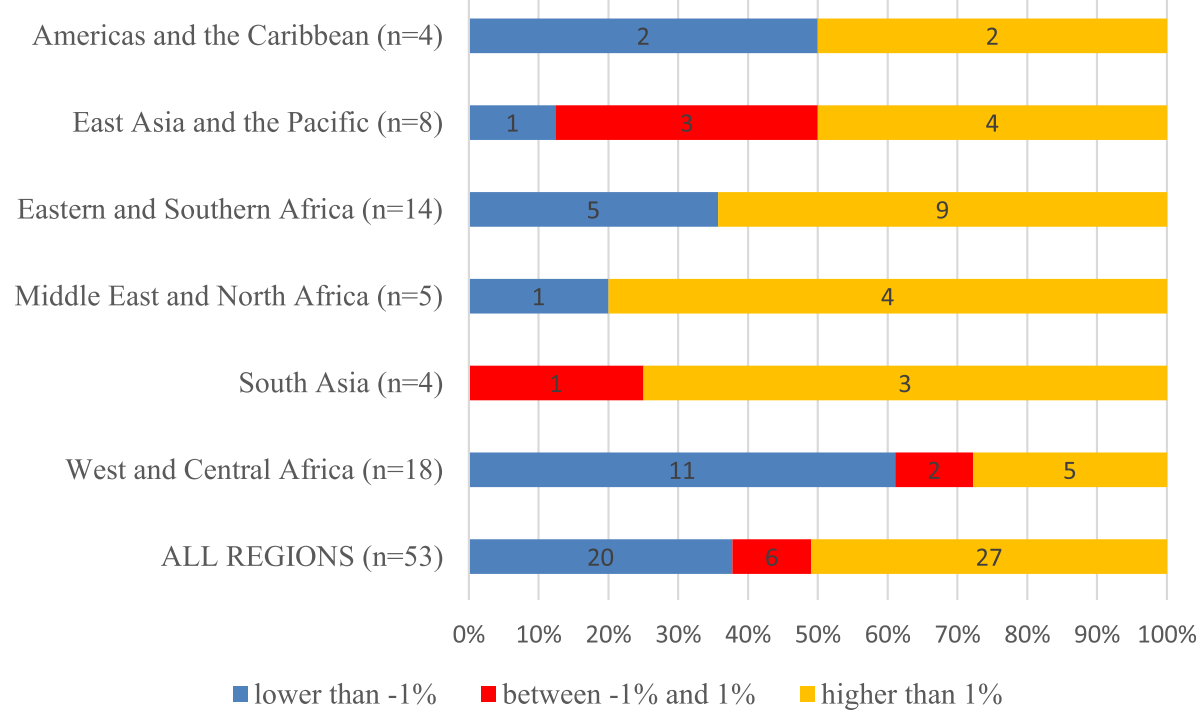

Fig. 8 Average exponential growth rate (AEGR) in the number of physicians, nurses and midwives per 10000 population for 53 Countdown countries with more than one data point between 2004 and the latest available year, by UNICEF region

Bangladesh, Mali, Togo and Ivory Coast), i.e. the number of physicians grew while the number of nurses and midwives contracted. The reversed pattern, i.e. a null or positive AEGR for nurses and midwives but a negative one for physicians, was observed in five countries (Lao PDR, Ghana, Yemen, Botswana and Zimbabwe).

Looking to the future, Fig. 11 shows the required AEGR in SHP numbers that each of the 63 Countdown countries with SHP density below 44.5 SHPs per 10000 population require to reach that threshold by 2030. Six countries (Botswana, China, Gabon, India, Peru and Viet Nam) require a solid AEGR $(<5 \%)$ and a further 20 countries
(Angola, Bolivia, Comoros, Congo, Djibouti, Ghana, Guatemala, Indonesia, Lesotho, Morocco, Myanmar, Nepal, Nigeria, Pakistan, São Tomé and Principe, Solomon Islands, Sudan, Swaziland, Uganda, Zimbabwe) require a very solid AEGR (5-10\%). However, the remaining 37 countries require an extraordinary AEGR of $10 \%$ or above, including 13 African countries requiring an unlikely AEGR of $15 \%$ or above.

HRH metrics: a rapid review of the literature

The analysis of the 86 studies included in the rapid review lead to the identification of three different groups,

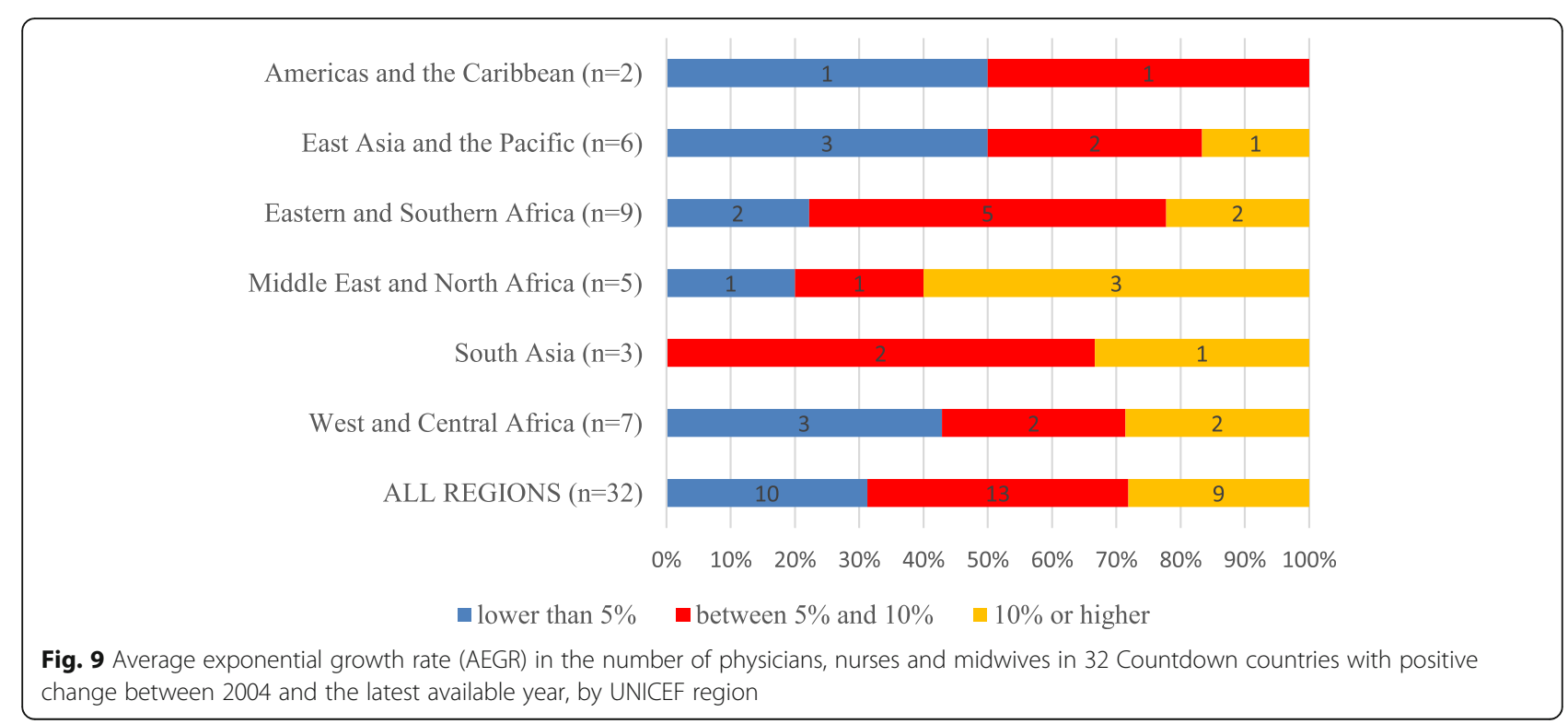




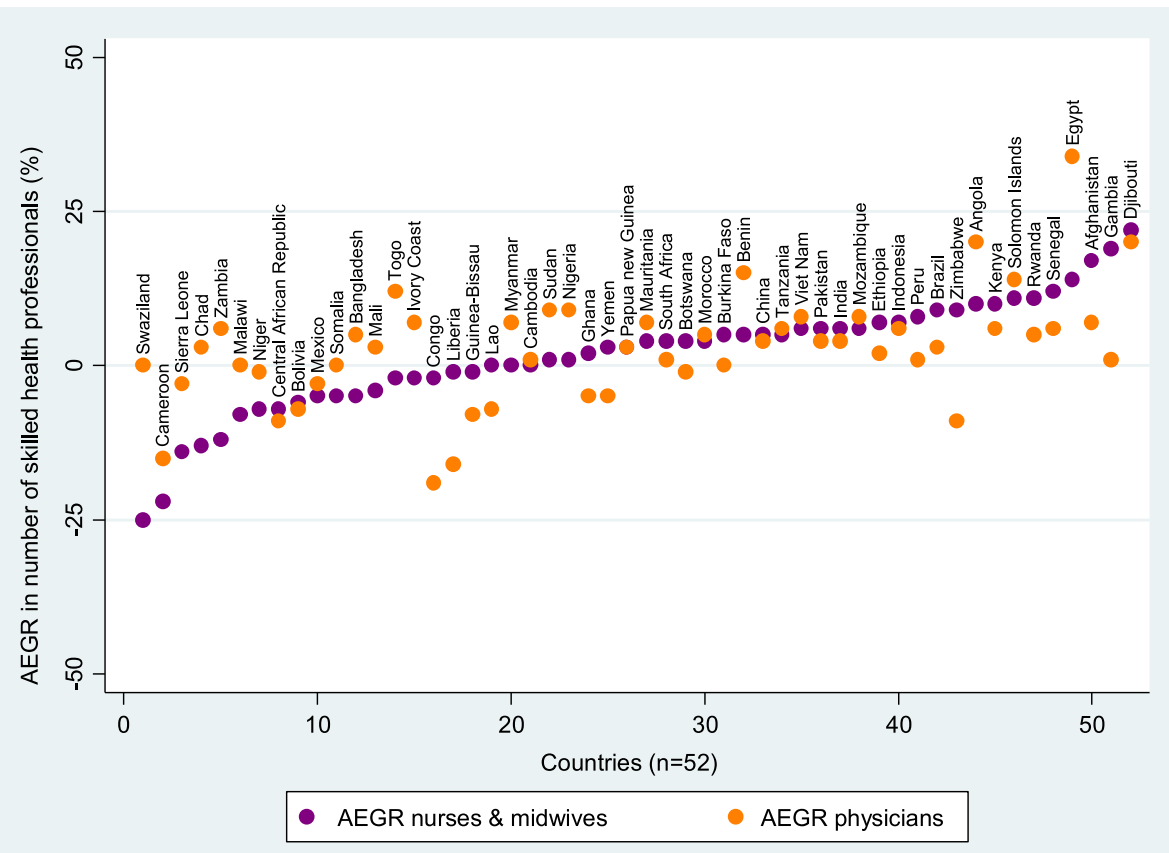

Fig. 10 Average exponential growth rate (AEGR) in the number of (a) nurses and midwives and (b) physicians for 52 Countdown countries with positive change between 2004 and the latest available year, and data disaggregated by cadre

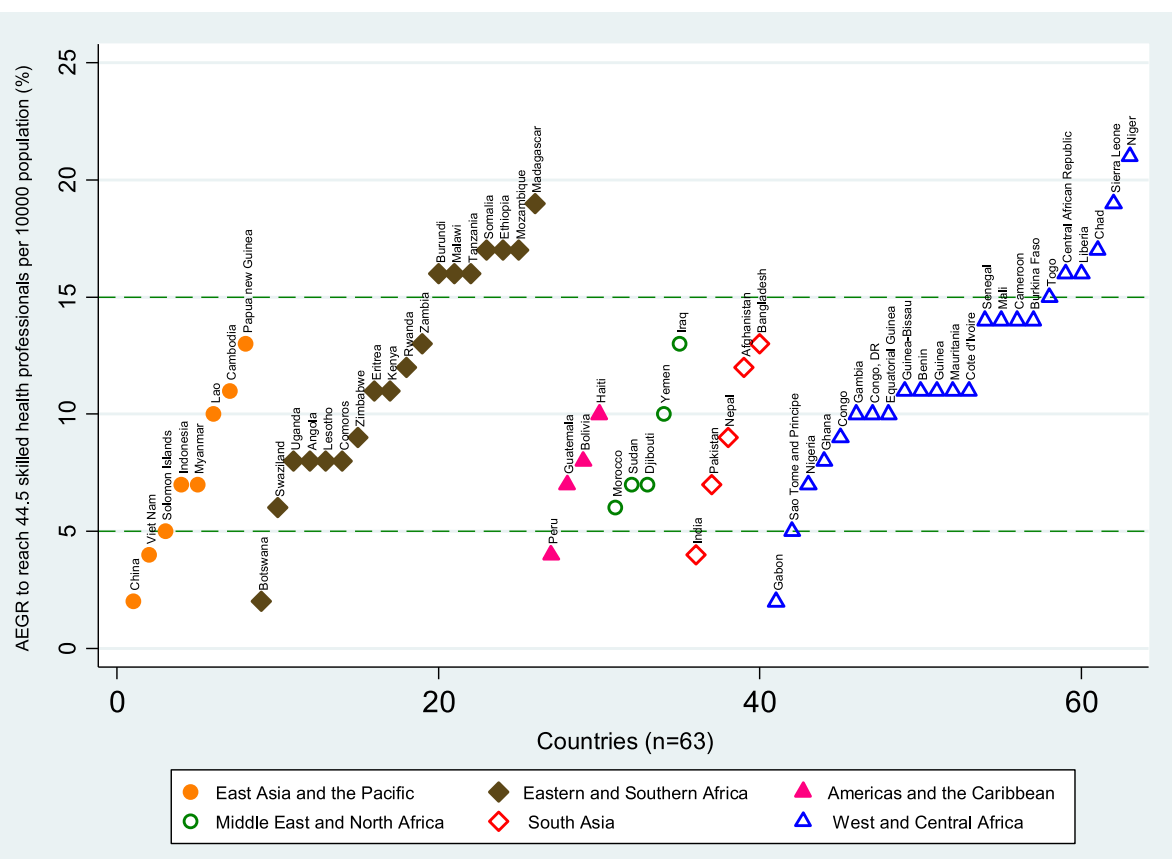

Fig. 11 Average exponential growth rate (AEGR) in the number of physicians, nurses and midwives required to reach 44.5 per 10000 population by 2030 for the 63 Countdown countries currently below this threshold, by UNICEF region 
based on the type of methods used (Table 1): (1) basic descriptive and inferential statistics, (2) regression analysis and (3) workforce modelling.

The most frequently used method was basic descriptive and inferential statistics. These studies provided snapshots of the health workforce situation in terms of its availability, geographic distribution [32-48] and other characteristics such as socio-demographic [49-52], deployment and conditions of employment [53-57]. Several studies aiming to characterise migration flows [58-64] and the skill mix of the health workforce $[58,65,66]$ also applied this type of method. Others explored planning and health information systems [67-75]. Some focused on measuring inequality $[76,77]$ (both in terms of socio-economic status and of urban/rural differentials) in access to the health workforce. The results were usually expressed as headcounts by professional cadre and/or as workforce densities.

Regression analysis was the second most common type of method used. The two main types of studies using regression analysis were (1) studies examining the relationship between the availability of health workers and health outcome and health care coverage indicators [27, 78-89] mainly maternal and child outcomes and immunisation rates and (2) studies exploring the relationship between the demographic, socioeconomic and employment characteristics of the workforce and its availability [90-95]. Some studies also focused on workforce planning issues [96-98].

Workforce modelling studies included approaches to predict future health workforce requirements based on different policy scenarios, most often observed in highincome settings. Among the more sophisticated workforce modelling approaches were those based on systems dynamics [99-101] or need for health services [102-104]. Other modelling approaches included supply-based modelling (e.g. focusing on the production and inflows of health workers) [105-108], demand-based modelling (e.g. estimating future health service utilisation) [109] or both $[36,110-112]$.

Table 2 shows that most studies (and all of the modelling studies) used two or more sources of workforce data. Descriptive studies were most likely to use a combination of primary data collection and analysis of secondary sources, while workforce modelling studies nearly all used secondary analysis only.
Out of the 86 studies, 118 data sources were identified: 32 studies combined different types of data sources. National data sources (including professional councils' registers, ministries of health, national statistics bureaux and national censuses) were the most commonly used data sources across all types of methods. The studies which most often used global data sources (including the WHO Global Health Workforce Statistics Database, WHO health indicator statistics and World Bank socioeconomic indicators) were those using regression analysis. 'Sub-national' data sources (administrative databases in, e.g. provinces, districts or health facility registers) were most commonly used in studies using basic descriptive and inferential statistics. Workforce planning studies mostly relied on national-level data sources.

The literature review showed that sophisticated workforce planning approaches are being developed, particularly in high-income settings. These planning approaches look at the population need for health services and align with identified health service priorities. They estimate future health workforce requirements based on populations needs and can be adjusted over time [4, 113, 114]. Such approaches should be considered in all settings, particularly where resources are limited, and are feasible if $\mathrm{HRH}$ information systems (HRIS) or national health workforce accounts (NHWA) are already in place $[2,9,115]$.

\section{Discussion}

Although this study shows that half of the Countdown countries for which data are available have seen an increase in SHP density and 60\% in SHP numbers since 2004, most remain affected by critical needs-based shortages. This situation has hindered the achievement of the MDGs [116], and the fact that so many countries have fewer than the 44.5 SHPs per 10000 population needed to deliver on the health-related SDGs will negatively affect progress towards these goals. The demand for high, sustained and equitable coverage with proven life-saving interventions will continue to rise especially in sub-Saharan Africa, a challenge compounded by its significant population growth. In many countries, the required scale-up of SHPs may be unrealistic given the resources available and the present capacity of production of qualified health workers.

Table 1 Number of studies by type of method used and country income group

\begin{tabular}{llllll}
\hline Type of method & \multicolumn{2}{l}{ Income level of study setting } & & Total \\
\cline { 2 - 5 } & All levels & Low & Lower-middle & Upper-middle & High \\
\hline Basic descriptive and inferential statistics & 1 & 17 & 9 & 8 & 13 \\
Regression analysis & 4 & 5 & 6 & 3 & 5 \\
Workforce modelling & 0 & 2 & 2 & 1 & 23 \\
Total & 5 & 24 & 17 & 12 & 10 \\
\hline
\end{tabular}


Table 2 Number and type of sources of data by type of method

\begin{tabular}{llll}
\hline Type of method & Basic descriptive and inferential statistics & Regression & Workforce modelling \\
\hline $\begin{array}{l}\text { Number of papers } \\
\text { Number of sources used }\end{array}$ & 48 & 23 & 15 \\
1 & $14(29 \%)$ & $7(30 \%)$ & 0 \\
2 & $15(31 \%)$ & $5(22 \%)$ & $4(27 \%)$ \\
3 or more & $19(40 \%)$ & $11(48 \%)$ & $11(73 \%)$ \\
Type of source & & & 21 \\
Primary data collection & $7(15 \%)$ & $4(17 \%)$ & 0 \\
Analysis of secondary sources & $30(62 \%)$ & $18(78 \%)$ & $14(93 \%)$ \\
Both & $11(23 \%)$ & $1(4 \%)$ & $1(13 \%)$ \\
\hline
\end{tabular}

On the basis of this study and similar analyses [117], it is unlikely that many low- and middle-income countries will be able to address effectively the shortage of health workers without significant additional investments. This will require strategies to mobilise additional resources and funding mechanisms that require long-term strategic planning exercises and a focus on cost-effective primary care delivery models [113]. The increasing diversity in the types of health worker (e.g. by reviewing the scopes of practice of certain cadres, for example expanding the functions of nurses, introducing new cadres such as community-based and mid-level health practitioners, changing the skill mix of cadres placed closer to communities) can be an effective way to make services available, accessible and acceptable and could represent a sustainable strategy to improve health outcomes in some countries. There is also emerging evidence that a more diverse skill mix can represent a cost-effective policy option in low-income settings [118].

Despite the detailed analysis of the $\mathrm{HRH}$, due to data limitations, this study was unable to go beyond descriptive analysis using density as the main $\mathrm{HRH}$ measure. The data published in the Global Health Workforce Statistics database are mined from multiple sources and vary within and across countries. The database is largely composed of data from national administrative sources which may be less rigorous on standardised definitions and occupational classifications, as opposed to data collected for differential statistical analysis. It is also noted that national occupation titles and classifications change over time within a country and across countries, posing a challenge to the interpretation of any trend analysis such as the one described here. By and large, administrative sources are confined to the public sector; so the growing private sector in many countries is commonly under- or unrepresented. Hence, there are limitations to HRH data availability and in some instances quality, and far less emphasis on the other dimensions of effective coverage: accessibility, acceptability and quality [119]. Presently, the calculated AEGRs offer the most that can be gleaned from the available data and unfortunately little to no data are reliably and representatively available on the determinants of HRH changes in these countries.

Even if a country has sufficient numbers of health workers, health outcomes will only improve if attention is paid to the other dimensions of effective coverage at sub-national levels because people may be prevented from using services due to geographical, financial or other barriers [120] or may choose not to use services due to concerns over acceptability or quality [121].

HRH data are multi-sectoral and current mechanisms to collect and collate health workforce data routinely do not always include the private and NGO sectors. In many countries, the private sector meets a high proportion of the demand for health services [122], so if excluded, workforce planning is highly compromised and biased. More critically, accurate data on the number of health workers trained using public funds and go on to work in the private sector would enable governments to better manage fiscal resources and the extent of 'internal brain drain'.

The health-related targets of the SDGs emphasise the need for UHC and therefore equity of access to health care [123]. The lack of standardised, disaggregated and interoperable data on the health workforce limits the capacity of countries to systematically and regularly identify gaps in health worker availability $[20,124]$, whether these gaps relate to geography, socio-economic group, ethnic group, age, gender or to other variables. Countries cannot address unmet need unless they have reliable information about the nature, size and location of these gaps [113].

The literature review showed that some descriptive studies also focus on the distribution of the health workforce; however, these are often based on cross-sectional data collected from a variety of sources which are not always designed for this specific purpose [125]. Systems for monitoring the health workforce, such as an HRIS embedded in a health management information system (HMIS) [125], should be developed and take into 
account measures of accessibility, acceptability and quality as well as availability at both national and subnational levels [9]. It is also important systematically to collect and analyse information on the dynamics of the health labour market, such as production, inflows and outflows, distribution, retention and regulation and their determinants. These factors interrelate to impact the availability and quality of health services.

NHWA is a WHO-led initiative which aims "to standardise the health workforce information architecture and interoperability as well as tracking HRH policy performance toward universal health coverage" by defining core indicators and data characteristics [124, 126, 127]. This approach has the potential to break new ground in the standardisation and systematic collection of relevant health workforce information to inform planning and policy development [115]. NHWA build upon existing HRIS in a modular fashion which will be supported by a global digital tool [128]. It is anticipated that, as the implementation of NHWA develops, a standard set of indicators will emerge that will allow more nuanced monitoring of the availability and efficacy of the health workforce [115].

In some countries, concerted investments are needed to professionalise and institutionalise health workforce planning and management. The rapid review shows that innovative approaches are being developed for workforce planning [129] which are less labour-intensive than traditional methods and therefore may represent an opportunity for low- and middle-income countries to introduce systems which are less costly to implement and maintain.

The paper has identified the main sources of $\mathrm{HRH}$ data: we recognise that there are limitations in the accuracy and completeness of some of data that can be accessed from these sources and that not all sources have the same strengths and weaknesses as a source of $\mathrm{HRH}$ data. In particular, survey-based primary sources and secondary sources may be at risk of being incomplete, out of date or inaccurate due to a lack of full understanding on the part of the researchers, or a focus on 'what is there' in terms of data, rather than 'what is needed'. It should also be noted that in some cases 'official' sources may also fall short of complete accuracy, and if these are then used as the basis for input into international databases, then the risk is compounded. International agencies recognise this risk and devote time and effort to clarifying data returns with the original source within the country, but this is not foolproof. Using a coherent approach to data reporting and analysis based on a template of core indictors as proposed by the implementation of NHWA would gradually eliminate such data errors and shortfalls.

Last but not least, the confinement of reported HRH statistics to SHPs has to be overcome. For example, data are commonly requested on community health workers
(CHWs) which have recently been recognised as a costeffective cadre in delivering certain health services [118], and some countries have chosen to deploy significant numbers of CHWs as a response to the shortage of SHPs, which is not reflected in these analyses. This situation is in part a result of poor reporting of CHW numbers in countries' official statistics, but mainly due to the lack of standardised definitions of CHWs in terms of training, skills and functions. Until these issues are properly addressed, any global monitoring of those cadres will remain flawed.

The rapid literature review methodology is not as clearly developed as the one established for systematic reviews, so the review may not have been fully comprehensive. In addition, the search terms used are not exhaustive, and the review was conducted by a single researcher, which could have introduced a selection bias. Therefore the findings of the literature review require a careful interpretation.

\section{Conclusions}

The achievement of health-related SDGs remains conditional on the existence of a sufficient health workforce that is well-planned, deployed and appropriately managed and supported to meet population needs. The skill mix, composition and efficiency of such a workforce can only be determined accurately using high-quality and comprehensive data. In many countries, and especially low- and middleincome countries, such data are close to absent. This study adds to the growing body of knowledge on the health workforce trends and on shortcomings of existing health workforce data (see for example, Gupta et al. [130]) by (1) exploring the current need for SHP in maternal and newborn health in Countdown countries in 2015, estimating the necessary growth to meet the HRH requirements to achieve UHC, and (2) highlighting the limitations of the current $\mathrm{HRH}$ data sources, $\mathrm{HRH}$ metrics and methods of analysis of HRH data. The paper explains the need for a harmonised, global approach to strengthen health workforce knowledge and the evidence base. The Countdown to 2015 collaboration has now evolved into the 'Countdown to 2030 for Reproductive, Maternal, Newborn, Child, and Adolescent Health and Nutrition' initiative, which emphasises the need to build, beyond 2015, a solid foundation of baseline data that can be used to track progress and back up the accountability rhetoric with real resources to generate sound data [131], a critical dimension of this relates to the health workforce and the implementation of NHWA.

\section{Additional file}

Additional file 1: Table S1. Initial (either 2004 or closest year before 2004) and latest year with data on SHP numbers in WHO Global Health Workforce Statistics database and most recent estimate of SHP density for 74 Countdown countries. (DOC 86 kb) 


\section{Abbreviations}

AEGR: Average exponential growth rate; CHW: Community health worker; GDP: Gross domestic product; GNI: Gross national income; HMIS: Health management information system; HRH: Human resources for health; HRIS: Human resources information system; MDG: Millennium Development Goal; MNH: Maternal and newborn health; NGO: Non-governmental organisation; NHWA: National health workforce accounts; SDG: Sustainable development goal; SHP: Skilled health professional (in this context, physician, nurse or midwife); UHC: Universal health coverage; UNICEF: United Nations Children's Fund; WHO: World Health Organization

\section{Acknowledgements}

We gratefully acknowledge Cesar Victora, Jennifer Requejo and Peter Berman of the Countdown Scientific Review Group, who provided valuable comments on an early draft of this paper.

\section{Funding}

This study was supported by a sub-grant from the U.S. Fund for UNICEF under their Countdown to 2015 for Maternal, Newborn and Child Survival Grant from the Bill and Melinda Gates Foundation.

\section{Availability of data and materials}

The datasets analysed during this study are available from the corresponding author on reasonable request.

\section{Authors' contributions}

AS, GC and JC conceptualised the study. AS, FPM, SCL and AN designed the study. SCL reviewed the literature and checked all references. TK collated and quality checked the WHO database from which the data used in the analysis were extracted and drafted the sections of the paper which refer to this database. SCL checked and formatted the extracted data. All statistical analysis was performed by FPM. AN wrote the initial draft of the 'Background', 'Results' and 'Discussion' sections of the paper, FPM wrote the initial draft of the 'Methods' section and SCL wrote the sections pertaining to the rapid literature review. GC, JC, JB, GD, TK and AS contributed important revisions to the paper. All authors approved the final submitted version.

\section{Competing interests}

The authors declare that they have no competing interests.

\section{Consent for publication}

Not applicable.

\section{Ethics approval and consent to participate}

Not applicable.

\section{Author details}

IInstituto de Cooperación Social Integrare, calle Balmes 30, 3-1, 08007 Barcelona, Spain. ${ }^{2}$ Health Systems and Innovations, WHO Headquarters, Geneva, Switzerland. ${ }^{3} \mathrm{Gl}$ lobal Health Workforce Network, WHO Headquarters, Geneva, Switzerland. ${ }^{4}$ School of Nursing Midwifery and Health, University of Technology Sydney, Sydney, Australia. ${ }^{5}$ Global Health and Tropical Medicine, Instituto de Higiene e Medicina Tropical, Universidade Nova de Lisboa, Lisbon, Portugal.

Received: 12 February 2016 Accepted: 9 February 2017

\section{Published online: 15 February 2017}

\section{References}

1. Campbell J, Dussault G, Buchan J, Pozo-Martin F, Guerra Arias M, Leone C, et al. A universal truth: no health without a workforce. Forum report. Third global forum on human resources for health, Recife, Brazil. Geneva: Global Health Workforce Alliance and World Health Organization; 2013.

2. Nigenda GGJ, Machado MH, Ruiz FF, Carrasco W, Moline PP, Girardi SS. Towards the construction of health workforce metrics for Latin America and the Caribbean. Hum Resour Health. 2011;9:24. Available from: http://www.humanresources-health.com/content/pdf/1478-4491-9-24pdf. Accessed 12 Feb 2017.

3. Centre for Workforce Intelligence. Robust workforce planning framework: an introduction [Internet]. London; 2014. Available from: http://www.cfwi.org.uk/ publications/robust-workforce-planning-an-introduction. Accessed 12 Feb 2017.
4. Ozgediz D, Hsia R, Weiser T, Gosselin R, Spiegel D, Bickler S, et al. Population health metrics for surgery: effective coverage of surgical services in low-income and middle-income countries. World J Surg. 2009;33:1-5. Available from: http://www.ncbi.n/m.nih.gov/pubmed/18958518. Accessed 12 Feb 2017

5. WHO, World Bank, USAID. In: Dal Poz MR, Gupta N, Quain E, Soucat AL, editors. Handbook on monitoring and evaluation of human resources for health: with special applications for low- and middle-income countries. Geneva: World Health Organization; 2009.

6. Ono T, Lafortune $G$, Schoenstein M. Health workforce planning in OECD countries: a review of 26 projection models from 18 countries. Paris: OECD Health Working Papers, No. 62, OECD Publishing; 2013.

7. Zhao F, Squires N, Weakliam D, Van Lerberghe W, Soucat A, Toure K, et al. Investing in human resources for health: the need for a paradigm shift. Bull World Health Organ. 2013;91:799-799A. Available from: http://www.who.int/ entity/bulletin/volumes/91/11/13-118687.pdf. Accessed 12 Feb 2017.

8. World Health Organization. Models and tools for health workforce planning and projections. Hum. Resour. Heal. Obs. Geneva: WHO; 2010.

9. Diallo K, Zurn P, Gupta N, Dal Poz M. Monitoring and evaluation of human resources for health: an international perspective. Hum Resour Health. 2003; 1:3. Available from: http://www.ncbi.nlm.nih.gov/pmc/articles/PMC179874/. Accessed 12 Feb 2017

10. ILO. World Social Protection Report 2014/15. Geneva: International Labour Office; 2014.

11. Bryce J, Victora C, Berman P, Lawn J, Mason E, Starrs A, et al. Fulfilling the health agenda for women and children. The 2014 Report. Geneva: World Health Organization; 2014.

12. Countdown to 2030. Countdown to 2030 for Reproductive, Maternal, Newborn, Child, and Adolescent Health and Nutrition [Internet]. 2016 [cited 2017 Jan 12]. Available from: http://www.countdown2015mnch.org/about-countdown.

13. WHO. Working together for health. The World Health Report 2006. Geneva: World Health Organization; 2006.

14. GHWA. Global key messages [Internet]. 2014 [cited 2015 Sep 4]. Available from: http://www.who.int/workforcealliance/media/key_messages_2014.pdf.

15. World Health Organization. Global strategy on human resources for health: Workforce 2030 (draft 1.0 submitted to the Executive Board (138th session) [Internet]. Geneva: World Health Organization; 2016. Available from: http://www. who.int/hrh/resources/global_strategyHRH.pdf?ua=1. Accessed 12 Feb 2017.

16. Bossert TJ, Ono T. Finding affordable health workforce targets in lowincome nations. Health Aff (Millwood). 2010;29:1376-82. Available from: http://www.ncbi.n/m.nih.gov/pubmed/20606191. Accessed 12 Feb 2017

17. Scheffler R, Fulton B. Needs-based estimates for the health workforce. In: Soucat A, Scheffler R, Donald K, editors. Labor Mark. Heal. Work. Africa A New Look Cris. [Internet]. Washington: World Bank; 2013. Available from: http:// elibrary.worldbank.org/content/book/9780821395554. Accessed 12 Feb 2017.

18. Farahani M, Subramanian SV, Canning D. The effect of changes in health sector resources on infant mortality in the short-run and the long-run: a longitudinal econometric analysis. Soc Sci Med. 2009;68:1918-25. Available from: http://www.ncbi.n/m.nih.gov/pubmed/19362762. Accessed 12 Feb 2017

19. Fulton BD, Scheffler RM, Sparkes SP, Auh EY, Vujicic M, Soucat A. Health workforce skill mix and task shifting in low income countries: a review of recent evidence. Hum Resour Health. 2011;9:1.

20. World Health Organization. WHO Country Assessment Tool on the uses and sources for human resources for health $(\mathrm{HRH})$ data. Geneva: World Health Organization; 2012.

21. WHO. Global Health Observatory Data Repository [Internet]. 2013 [cited 2013 Jun 1]. Available from: http://apps.who.int/gho/data/view.main.

22. UN Population Division. World Population Prospects: The 2012 Revision [Internet]. 2015 [cited 2015 Jul 1]. Available from: http://esa.un.org/wpp/ unpp/panel_population.htm.

23. World Bank. Country and Lending Groups [Internet]. 2015 [cited 2015 Sep 4]. Available from: http://data.worldbank.org/about/country-and-lending-groups.

24. WHO, UNFPA, UNICEF, World Bank. Trends in maternal mortality: 1990 to 2013. Geneva: World Health Organization; 2014.

25. Healthy Newborn Network. Newborn numbers [Internet]. 2015 [cited 2015 Jul 1]. Available from: http://www.healthynewbornnetwork.org/page/newborn-numbers.

26. UN Inter-agency Group for Child Mortality Estimation. Levels and trends in child mortality. UNICEF: New York; 2014

27. Anand S, Bärnighausen T. Human resources and health outcomes: crosscountry econometric study. Lancet. 2004;364:1603-9. 
28. WHO, UNICEF, UNFPA, World Bank, UN Population Division. Trends in Maternal Mortality: 1990 to 2015 [Internet]. 2015. Available from: http:// www.who.int/reproductivehealth/publications/monitoring/maternalmortality-2015/en/. Accessed 12 Feb 2017.

29. Cousens S, Blencowe H, Stanton C, Chou D, Ahmed S, Steinhardt L, et al. National, regional, and worldwide estimates of stillbirth rates in 2009 with trends since 1995: a systematic analysis. Lancet. 2011;377:1319-30.

30. The DHS Program. Maternal Health [Internet]. 2015 [cited 2015 Sep 4]. Available from: http://www.dhsprogram.com/Topics/Maternal-Health.cfm.

31. UN Maternal Mortality Estimation Inter-agency Group. UNICEF data: monitoring the situation of children and women [Internet]. 2014 [cited 2015 Sep 4]. Available from: http://data.unicef.org/maternal-health/maternalmortality\#sthash.CuApZOge.dpuf.

32. Agboghoroma CO, Gharoro EP. Coverage and distribution of obstetricians and gynecologists in Nigeria. Int J Gynaecol Obstet. 2015;129:50-3.

33. Ahmed SM, Hossain MA, Rajachowdhury AM, Bhuiya AU. The health workforce crisis in Bangladesh: shortage, inappropriate skill-mix and inequitable distribution. Hum Resour Health. 2011;9:3.

34. Carson BE, Bailie RS. National health workforce in discrete Indigenous communities. Aust N Z J Public Health. 2004;28:235-45.

35. Ferrinho P, Siziya S, Goma F, Dussault G. The human resource for health situation in Zambia: deficit and maldistribution. Hum Resour Health. 2011;9:30.

36. Bigbee JL. Relationships between nurse- and physician-to-population ratios and state health rankings. Public Health Nurs. 2008;25:244-52.

37. Ghosh B. Health workforce development planning in the Sultanate of Oman: a case study. Hum Resour Health. 2009;7:47.

38. Gross JM, Riley PL, Kiriinya R, Rakuom C, Willy R, Kamenju A, et al. The impact of an emergency hiring plan on the shortage and distribution of nurses in Kenya: the importance of information systems. Bull World Health Organ. 2010;88:824-30

39. Gow J, George G, Mutinta G, Mwamba S, Ingombe L. Health worker shortages in Zambia: an assessment of government responses. J Public Health Policy. 2011;32:476-88.

40. Gupta N, Dal Poz MR. Assessment of human resources for health using cross-national comparison of facility surveys in six countries. Hum Resour Health. 2009;7:22.

41. Gupta N, Maliqi B, Franca A, Nyonator F, Pate MA, Sanders D, et al. Human resources for maternal, newborn and child health: from measurement and planning to performance for improved health outcomes. Hum Resour Health. 2011;9:16.

42. Heywood PF, Harahap NP. Human resources for health at the district level in Indonesia: the smoke and mirrors of decentralization. Hum Resour Health. 2009; 7:6.

43. Landry MD, Ricketts TC, Verrier MC. The precarious supply of physical therapists across Canada: exploring national trends in health human resources (1991 to 2005). Hum Resour Health. 2007;5:23.

44. Ly A, Kouanda S, Ridde V. Nursing and midwife staffing needs in maternity wards in Burkina Faso referral hospitals. Hum Resour Health. 2014;12:S8.

45. Manzi F, Schellenberg JA, Hutton G, Wyss K, Mbuya C, Shirima K, et al. Human resources for health care delivery in Tanzania: a multifaceted problem. Hum Resour Health. 2012;10:3.

46. Olsen OE, Ndeki S, Norheim OF. Human resources for emergency obstetric care in northern Tanzania: distribution of quantity or quality? Hum Resour Health. 2005;3:5.

47. Palmer JJ, Chinanayi F, Gilbert A, Pillay D, Fox S, Jaggernath J, et al. Mapping human resources for eye health in 21 countries of sub-Saharan Africa: current progress towards VISION 2020. Hum Resour Health. 2014;12:44.

48. Rao KD, Bhatnagar A, Berman P. So many, yet few: human resources for health in India. Hum Resour Health. 2012;10:19.

49. He XZ, Cyran E, Salling M. National trends in the United States of America physician assistant workforce from 1980 to 2007. Hum Resour Health. 2009;7:86.

50. Keane S, Smith T, Lincoln M, Fisher K. Survey of the rural allied health workforce in New South Wales to inform recruitment and retention. Aust J Rural Health. 2011:19:38-44.

51. Schofield DJ, Beard JR. Baby boomer doctors and nurses: demographic change and transitions to retirement. Med J Aust. 2005;183:80-3.

52. Xu H, Zhang W, Zhang X, Qu Z, Wang X, Sa Z, et al. Longitudinal study of rural health workforce in five counties in China: research design and baseline description. Hum Resour Health. 2013;11:17.

53. Buchan J, Fronteira I, Dussault G. Continuity and change in human resources policies for health: lessons from Brazil. Hum Resour Health. 2011;9:17.
54. Chankova S, Muchiri S, Kombe G. Health workforce attrition in the public sector in Kenya: a look at the reasons. Hum Resour Health. 2009;7:58.

55. de Vasconcellos Coelho MCR, Assuncao AA, Belisario SA. Employment and sociodemographic characteristics: a study of increasing precarity in the health districts of Belo Horizonte, Brazil. Hum Resour Health. 2009;7:56

56. Hanrahan NP, Hartley D. Employment of advanced-practice psychiatric nurses to stem rural mental health workforce shortages. Psychiatr Serv. 2008:59:109-11.

57. Leach MJ, Segal L, May E. Lost opportunities with Australia's health workforce? Med J Aust. 2010;193:167-72.

58. Baral B, Prajapati R, Karki KB, Bhandari K. Distribution and skill mix of health workforce in Nepal. J Nepal Health Res Counc. 2013;11:126-32.

59. Clemens MA, Pettersson G. New data on African health professionals abroad. Hum Resour Health. 2008;6:1.

60. Dovlo D. Migration of nurses from sub-Saharan Africa: a review of issues and challenges. Health Serv Res. 2007:42:1373-88.

61. El-Jardali F, Dumit N, Jamal D, Mouro G. Migration of Lebanese nurses: questionnaire survey and secondary data analysis. Int J Nurs Stud. 2008:45: 1490-500.

62. Forcier M, Simoens S, Giuffrida A. Impact, regulation and health policy implications of physician migration in OECD countries. Hum Resour Health. 2004;2:12.

63. Negin J, Rozea A, Cloyd B, Martiniuk ALC. Foreign-born health workers in Australia: an analysis of census data. Hum Resour Health. 2013;11:69.

64. Tankwanchi ABS, Ozden C, Vermund SH. Physician emigration from subSaharan Africa to the United States: analysis of the 2011 AMA physician masterfile. PLoS Med. 2013;10:e1001513. Available from: http://www. plosmedicine.org/article/fetchObject.action?uri=info:doi/10.1371/journal. pmed. 1001513\&representation=PDF.

65. Dgedge M, Mendoza A, Necochea E, Bossemeyer D, Rajabo M, Fullerton J. Assessment of the nursing skill mix in Mozambique using a task analysis methodology. Hum Resour Health. 2014;12:5.

66. Walsh A, Ndubani P, Simbaya J, Dicker P, Brugha RR. Task sharing in Zambia: HIV service scale-up compounds the human resource crisis. BMC Health Serv Res. 2010;10:272.

67. Buivydiene J, Starkiene L, Smigelskas K. Healthcare reform in Lithuania: evaluation of changes in human resources and infrastructure. Scand J Public Health. 2010:38:259-65.

68. Gebbie K, Merrill J, Sanders L, Gebbie EN, Chen DW. Public health workforce enumeration: beware the "quick fix". J Public Health Manag Pract. 2007;13:72-9.

69. Goma FM, Murphy GT, Libetwa M, MacKenzie A, Nzala SH, Mbwili-Muleya C, et al. Pilot-testing service-based planning for health care in rural Zambia. BMC Health Serv Res. 2014;14 Suppl 1:S7.

70. Hirschhorn LR, Oguda L, Fullem A, Dreesch N, Wilson P. Estimating health workforce needs for antiretroviral therapy in resource-limited settings. Hum Resour Health. 2006:4:1.

71. McQuide PA, Kolehmainen-Aitken R-L, Forster N. Applying the workload indicators of staffing need (WISN) method in Namibia: challenges and implications for human resources for health policy. Hum Resour Health. 2013;11:64.

72. Riley PL, Vindigni SM, Arudo J, Waudo AN, Kamenju A, Ngoya J, et al. Developing a nursing database system in Kenya. Health Serv Res. 2007;42:1389-405.

73. Spero JC, McQuide PA, Matte R. Tracking and monitoring the health workforce: a new human resources information system (HRIS) in Uganda. Hum Resour Health. 2011:9:6

74. Suphanchaimat R, Wisaijohn T, Thammathacharee N, Tangcharoensathien V. Projecting Thailand physician supplies between 2012 and 2030: application of cohort approaches. Hum Resour Health. 2013;11:3.

75. Waters KP, Zuber A, Willy RM, Kiriinya RN, Waudo AN, Oluoch T, et al. Kenya's health workforce information system: a model of impact on strategic human resources policy, planning and management. Int J Med Inform. 2013;82:895-902

76. Sousa A, Dal Poz MR, Carvalho CL. Monitoring inequalities in the health workforce: the case study of Brazil 1991-2005. PLoS One. 2012;7:e33399. Available from: http://www.plosone.org/article/fetchObject.action?uri=info: doi/10.1371/journal.pone.0033399\&representation=PDF.

77. Theodorakis PN, Mantzavinis GD, Rrumbullaku L, Lionis C, Trell E. Measuring health inequalities in Albania: a focus on the distribution of general practitioners. Hum Resour Health. 2006;4:5.

78. Anand S, Fan W. Zhang J Zhang L, Ke Y, Dong Z et al. China's human resources for health: quantity, quality, and distribution. Lancet. 2008;372:1774-81. 
79. Barber SL, Gertler PJ, Harimurti P. The contribution of human resources for health to the quality of care in Indonesia. Health Aff (Millwood). 2007;26: w367-79.

80. El-Jardali F, Jamal D, Abdallah A, Kassak K. Human resources for health planning and management in the Eastern Mediterranean region: facts, gaps and forward thinking for research and policy. Hum Resour Health. 2007:5:9.

81. Faqir M, Zainullah P, Tappis H, Mungia J, Currie S, Kim YM. Availability and distribution of human resources for provision of comprehensive emergency obstetric and newborn care in Afghanistan: a cross-sectional study. Confl Health. 2015;9:9.

82. Kruk M, Prescott $M$, de Pinho $H$, Galea S. Are doctors and nurses associated with coverage of essential health services in developing countries? A crosssectional study. Hum Resour Health. 2009;7:27.

83. Mansoor GF, Hashemy P, Gohar F, Wood ME, Ayoubi SF, Todd CS. Midwifery retention and coverage and impact on service utilisation in Afghanistan. Midwifery. 2013;29:1088-94

84. Anand S, Barnighausen T. Health workers and vaccination coverage in developing countries: an econometric analysis. Lancet. 2007;369:1277-85.

85. Castillo-Laborde C. Human resources for health and burden of disease: an econometric approach. Hum Resour Health. 2011;9:4.

86. Madigan EA, Curet OL, Zrinyi M. Workforce analysis using data mining and linear regression to understand HIV/AIDS prevalence patterns. Hum Resour Health. 2008:6:2

87. Munga M, Maestad O. Measuring inequalities in the distribution of health workers: the case of Tanzania. Hum Resour Health. 2009;7:4

88. Tandi TE, Cho Y, Akam AJ-C, Afoh CO, Ryu SH, Choi MS, et al. Cameroon public health sector: shortage and inequalities in geographic distribution of health personnel. Int J Equity Health. 2015;14:43.

89. Curtis E, Wikaire E, Jiang Y, McMillan L, Loto R, Airini, et al. A tertiary approach to improving equity in health: quantitative analysis of the Maori and Pacific Admission Scheme (MAPAS) process, 2008-2012. Int J Equity Health. 2015;14:7.

90. Exavery A, Lutambi AM, Wilson N, Mubyazi GM, Pemba S, Mbaruku G. Gender-based distributional skewness of the United Republic of Tanzania's health workforce cadres: a cross-sectional health facility survey. Hum Resour Health. 2013;11:28.

91. George A, Springer C, Haughton B. Retirement intentions of the public health nutrition workforce. J Public Health Manag Pract. 2009;15:127-34

92. Pallikadavath S, Singh A, Ogollah R, Dean T, Stones W. Human resource inequalities at the base of India's public health care system. Health Place. 2013;23:26-32

93. Russo G, Ferrinho P, de Sousa B, Conceicao C. What influences national and foreign physicians' geographic distribution? An analysis of medical doctors' residence location in Portugal. Hum Resour Health. 2012;10:12.

94. Schofield D, Fletcher S, Page S, Callander E. Retirement intentions of dentists in New South Wales, Australia. Hum Resour Health. 2010;8:9

95. Gross JM, Rogers MF, Teplinskiy I, Oywer E, Wambua D, Kamenju A, et al, The impact of out-migration on the nursing workforce in Kenya. Health Serv Res. 2011:46:1300-18.

96. Gupta N, Castillo-Laborde C, Landry MD. Health-related rehabilitation services: assessing the global supply of and need for human resources. BMC Health Serv Res. 2011;11:276.

97. de Graaf-Ruizendaal WA, de Bakker DH. The construction of a decision tool to analyse local demand and local supply for GP care using a synthetic estimation model. Hum Resour Health. 2013:11:55.

98. Santric-Milicevic M, Vasic V, Marinkovic J. Physician and nurse supply in Serbia using time-series data. Hum Resour Health. 2013;11:27.

99. Barber P, Lopez-Valcarcel B. Forecasting the need for medical specialists in Spain: application of a system dynamics model. Hum Resour Health. 2010;8:24.

100. Ishikawa T, Ohba H, Yokooka Y, Nakamura K, Ogasawara K. Forecasting the absolute and relative shortage of physicians in Japan using a system dynamics model approach. Hum Resour Health. 2013;11:41.

101. Senese F, Tubertini P, Mazzocchetti A, Lodi A, Ruozi C, Grilli R. Forecasting future needs and optimal allocation of medical residency positions: the Emilia-Romagna Region case study. Hum Resour Health. 2015;13:7.

102. Tomblin MG. Eliminating the shortage of registered nurses in Canada: an exercise in applied needs-based planning. Health Policy. 2012;105:192-202.

103. Tomblin Murphy G, MacKenzie A, Guy-Walker J, Walker C. Needs-based human resources for health planning in Jamaica: using simulation modelling to inform policy options for pharmacists in the public sector. Hum Resour Health. 2014;12:67.
104. Van Greuningen M, Batenburg R, der Velden L. Ten years of health workforce planning in the Netherlands: a tentative evaluation of GP planning as an example. Hum Resour Health. 2012;10:21.

105. Buchan J, Seccombe I. Using scenarios to assess the future supply of NHS nursing staff in England. Hum Resour Health. 2012;10:16.

106. Jansen C, Codjia L, Cometto G, Yansane ML, Dieleman M. Realizing universal health coverage for maternal health services in the Republic of Guinea: the use of workforce projections to design health labor market interventions. Risk Manag Healthc Policy. 2014;7:219-32.

107. Takata H, Nagata H, Nogawa $H$, Tanaka $H$. The current shortage and future surplus of doctors: a projection of the future growth of the Japanese medical workforce. Hum Resour Health. 2011;9:14.

108. Tjoa A, Kapihya M, Libetwa M, Schroder K, Scott C, Lee J, et al. Meeting human resources for health staffing goals by 2018: a quantitative analysis of policy options in Zambia. Hum Resour Health. 2010:8:15.

109. Hagopian A, Micek M, Vio F, Gimbel-Sherr K, Montoya P. What if we decided to take care of everyone who needed treatment? Workforce planning in Mozambique using simulation of demand for HIV/AIDS care. Hum Resour Health. 2008:6:3.

110. Healy E, Kiely PM, Arunachalam D. Optometric supply and demand in Australia: 2011-2036. Clin Exp Optom. 2015:98:273-82.

111. Kober K, Van Damme W. Public sector nurses in Swaziland: can the downturn be reversed? Hum Resour Health. 2006:4:13.

112. Maier T, Afentakis A. Forecasting supply and demand in nursing professions: impacts of occupational flexibility and employment structure in Germany. Hum Resour Health. 2013;11:24.

113. GHWA. Health Workforce 2030: Towards a global strategy on human resources for health: synthesis paper of the thematic working groups. Geneva: World Health Organization; 2015.

114. Dussault G, Buchan J, Sermeus W, Padaiga Z. Assessing future health workforce needs. Brussels: WHO Regional Office for Europe; 2010.

115. World Health Organization. Human resources for health information system: minimum data set for health workforce registry [Internet]. Geneva; 2015. Available from: http://www.who.int/hrh/statistics/minimun_data_set.pdf. Accessed 12 Feb 2017.

116. Cometto G, Witter S. Tackling health workforce challenges to universal health coverage: setting targets and measuring progress. Bull World Health Organ. 2013:91:881-5.

117. Liu J, Goryakin A, Maeda A, Bruckner T, Scheffler R. Global Health Workforce Labor Market Projections for 2030. Hum Resour Health. 2017;15:11.

118. McPake B, Edoka I, Witter S, Kielmann K, Taegtmeyer M, Dieleman M, et al. Cost-effectiveness of community-based practitioner programmes in Ethiopia, Indonesia and Kenya. Bull World Heal Organ. 2015;93:631-9A.

119. Tanahashi T. Health service coverage and its evaluation. Bull World Health Organ. 1978;56:295-303

120. Scheffler RM, Liu JX, Kinfu Y, Dal Poz MR. Forecasting the global shortage of physicians: an economic- and needs-based approach. Bull World Health Organ. 2008;86:516-23B

121. Campbell J, Buchan J, Cometto G, David B, Dussault G, Fogstad H, et al. Human resources for health and universal health coverage: fostering equity and effective coverage. Bull World Heal Organ. 2013;91:853-63.

122. Forsberg B, Montagu D, Sundewall J. Moving towards in-depth knowledge on the private health sector in low- and middle-income countries. Health Policy Plan. 2011;26:11-3. doi:10.1093/heapol/czr050.

123. UN Department of Economic and Social Affairs. Open working group proposal for sustainable development goals [Internet]. 2015 [cited 2015 Jun 1]. Available from: https://sustainabledevelopment.un.org/focussdgs.html.

124. World Health Organization. Health in 2015: from MDGs to SDGs. Geneva; 2015.

125. Riley PL, Zuber A, Vindigni SM, Gupta N, Verani AR, Sunderland NL, et al. Information systems on human resources for health: a global review. Hum Resour Health. 2012;10:7.

126. World Health Organization. Global Strategy on Human Resources for Health: Workforce 2030. WHO: Geneva; 2016

127. Measurement and Accountability for Results in Health. The Roadmap for Health Measurement and Accountability [Internet]. Washington D.C.: 2015 Available from: http://www.who.int/hrh/documents/roadmap4healthmeasurement accountability.pdf?ua=1. Accessed 12 Feb 2017.

128. World Health Organization. National health workforce accounts: the knowledge-base for health workforce development towards universal health coverage. Geneva: WHO; 2015 
129. Centre for Workforce Intelligence. Horizon 2035: Health and care workforce futures: progress update. London; 2014.

130. Gupta N, Maliqi B, França A, Nyonator F, Pate MA, Sanders D, et al. Human resources for maternal, newborn and child health: from measurement and planning to performance for improved health outcomes. Hum. Resour. Health. 2011;9:DOI: 10.1186/1478-4491-9-16.

131. Requejo JH, Bryce J, Barros AJD, Berman P, Bhutta Z, Chopra M, et al. Countdown to 2015 and beyond: fulfilling the health agenda for women and children. The Lancet [Internet]. 30 AD; Available from: http://inkinghub. elsevier.com/retrieve/pii/S0140673614609259. Accessed 17 Feb 2017.

Submit your next manuscript to BioMed Central and we will help you at every step:

- We accept pre-submission inquiries

- Our selector tool helps you to find the most relevant journal

- We provide round the clock customer support

- Convenient online submission

- Thorough peer review

- Inclusion in PubMed and all major indexing services

- Maximum visibility for your research

Submit your manuscript at www.biomedcentral.com/submit 